\title{
PRECIPITATION AND CHARACTERIZATION OF NANO ALUMINA SURFACE COATING FOR SURFACE TREATED PARTIALLY STABILIZED ZIRCONIA
}

\author{
Sherine S. Stino*, Dalia M. Abdel-Hamid**, Madiha A. Shoeib ${ }^{* * *}$ and Azza A-Z. Hashem ${ }^{* * * *}$
}

\begin{abstract}
This study aimed at developing a controlled method for the precipitation of nano-alumina coating on surface treated yttria partially stabilized tetragonal zirconia (Y-TZP). Thirty zirconia discs were prepared and divided into 2 main groups: Polished zirconia (I) and sulfuric acid treated zirconia surface (II). These were further subdivided into 3 subgroups $(\mathbf{A}, \mathbf{B}, \mathbf{C})$ respectively: Control uncoated, surface coating with nano-structured alumina using aluminum nitride powder (AIN) as a reference method, and aluminum sulfate powder $\mathrm{Al}_{2}\left(\mathrm{SO}_{4}\right)_{3}$ as an alternative aluminum ion source. $\mathrm{X}$-ray diffraction (XRD) and scanning electron microscopy (SEM) were used for specimen's characterization. The XRD analysis revealed that IB, IIB exhibited wide peaks of nano-boehmite with peaks of unreacted AlN. After heat treatment, the lamellae transformed to nano-alumina. While IC, IIC groups revealed peaks of nano-boehmite only, transformed to nano-alumina by heat treatment. SEM of IB, IIB revealed bundles with nano-sized interlocked lamellae exhibiting large surface area. Groups IC, IIC had a leafy-like structure, randomly positioned nano-alumina crystals. Better retentive surface features were confirmed for IIB, IIC. It has been concluded that alumina precursors, $\mathrm{pH}$, temperature and stirring time are sensitive parameters in the co-precipitation of nano-alumina on zirconia. Aluminum nitride precursor provides superior zirconia nano-alumina coating quality than aluminum sulfate. Sulfuric acid surface pre-treatment of zirconia improved the retentive quality of the nano-alumina coating.
\end{abstract}

KEYWORDS: Zirconia; Nano-alumina; Sulfuric acid; Coating; Precipitation Characterization.

\footnotetext{
* Demonstrator, Biomaterials Department, Faculty of Oral and Dental Medicine, Cairo University. Cairo, Egypt. **Associate Professor, Biomaterials Department, Faculty of Oral and Dental Medicine, Cairo University. Cairo, Egypt. *** Professor, Chemistry \& Technology of Ceramic, Coating, Surface Treatment and Corrosion Control Department, Central Metallurgical Research and Development Institute (CMRDI). Cairo, Egypt. ***** Professor, Biomaterials Department, Faculty of Oral and Dental Medicine, Cairo University. Cairo, Egypt.
} 


\section{INTRODUCTION}

All-ceramic restorations have increased popularity in recent years and shown progressive improvement in properties ${ }^{(1)}$. The growing demand for both aesthetic and biocompatible restorations in dentistry has led to the development of toothcolored, metal-free systems for fixed prostheses ${ }^{(2)}$. One of these systems is the yttrium oxide stabilized tetragonal zirconia polycrystals (Y-TZP).

Although being superior in terms of its mechanical properties (strength, toughness, wear and fatigue resistance), chemical stability and biocompatibility, zirconia possessed a clinical problem in achieving good adhesion with intended synthetic substrates ${ }^{(3)}$. Being chemically bio-inert with non-polar surface resulted in retention related problem. Thus, it lacks the chemical adhesive potential or etchability ${ }^{(4,5)}$. Phosphoric acid $\left(\mathrm{H}_{3} \mathrm{PO}_{4}\right)$ or hydrofluoric acid (HF) etching is commonly used to roughen silica-based ceramics fitting surfaces. They create a rough; clean surface that improves the wettability and increases the surface area available for mechanical interlocking ${ }^{(5)}$. Unfortunately, these acids are not effective with zirconia to provide adequate mechanical interlocking. Furthermore, the lack of silica prevents the potential of chemical bonding through silanization process ${ }^{(5,6)}$.

Therefore, a satisfactory adhesive bonding to zirconia is still questionable and can greatly affect the restoration retention, clinical success and the longterm survival rate of zirconia-based restorations ${ }^{(3,6)}$. There is no clinical consensus on the appropriate bonding procedures. Considerable efforts are being made in order to develop alternative chemical and/ or mechanical surface modifications of Y-TZP ceramics ${ }^{(7)}$. These extensive trials include: airborne particle abrasion (or sandblasting) ${ }^{[8-10]}$, tribochemical silica coating ${ }^{(11-13)}$, application of fused glass micropearls ${ }^{(14,15)}$, selective infiltration etching ${ }^{(16-18)}$ and hot chemical etch solution ${ }^{(17,18)}$. Yet, the optimal method to enhance the bond strength to zirconia has not been reached.

Following the ongoing technological developments in the field of nanotechnology, nano-structured alumina coating (usually from aluminum nitride (AlN) precursor) of zirconia has been introduced in an attempt to improve bonding to zirconia ${ }^{(19-24)}$. It is a relatively new non-invasive process relies on functionalization of the Y-TZP zirconia surface by applying a nano-structured alumina coating to provide high surface area that promotes good wetting potential ${ }^{(19,22,23)}$.

However, the proper set of parameters needed for obtaining a simple, successful and durable coating from other aluminum salts precursor as well as its production feasibility are still not fully explored. Additionally, the use of sulfuric acid as a surface pretreatment for partially stabilized zirconia has not been used before. Therefore, the purposes of this study were to develop a predictable controlled method for the precipitation of nano-alumina coating on the sulfuric acid pretreated Y-TZP zirconia surface. Two different aluminum ion precursors: aluminum nitride (AlN) as a reference method ${ }^{(19-24)}$ and aluminum sulfate $\mathrm{Al}_{2}\left(\mathrm{SO}_{4}\right)_{3}$ as an alternative aluminum ion source were used. The pre-treated and/or coated zirconia specimens and the hydrolyzed powders were characterized for crystalline phase identification using the $\mathrm{X}$ ray diffraction (XRD). The microstructure of the pretreated and/or coated zirconia surfaces were examined by scanning electron microscopy (SEM).

\section{MATERIAL AND METHODS}

The materials used in the current study are listed in (Table 1); with the main substrate used Yttrium Partially Stabilized Zirconia (Y-TZP) and the chemical reagents being used for the deposition of the alumina layer. 
TABLE (1) Materials and their compositions used in the study, according to the manufacturers.

\begin{tabular}{|c|c|c|}
\hline Material & Main composition $(\mathrm{Wt} \%)$ & Manufacturer \\
\hline $\begin{array}{l}\text { Yttrium, partially stabilized zirconia, } \\
\text { poly-crystal ceramic blocks (Y-TZP) } \\
\text { as a core material (Amann Girrbach } \\
\text { Ceramill Zi } 71 \text { Blanks). }\end{array}$ & $\begin{array}{l}\text { Zirconium dioxide }\left(\mathrm{ZrO}_{2}\right) \text {, } \\
\text { Yttrium oxide }\left(\mathrm{Y}_{2} \mathrm{O}_{3}\right) 4.5-5.4 \% \text {, Hafnium } \\
\text { oxide }\left(\mathrm{HfO}_{2}\right)<5 \%,\left\{\mathrm{ZrO}_{2}+\mathrm{Y}_{2} \mathrm{O}_{3}+\mathrm{HfO}_{2}>\right. \\
99 \%\} \text {, Aluminium oxide }\left(\mathrm{Al}_{2} \mathrm{O}_{3}\right)<05 \% \text { and } \\
\text { other oxides }<0.5 \% \text {. }\end{array}$ & $\begin{array}{l}\text { Amann Girrbach AG, } \\
\text { Herrschaftswiesen, Koblach Austria. } \\
\text { Batch no. } 760174\end{array}$ \\
\hline $\begin{array}{l}\text { Zirconium oxide polishers (Ceramill } \\
\text { Polish- Lab Kit). }\end{array}$ & $\begin{array}{l}\text { Diamond medium wheel polishers, for } \\
\text { processing oxide ceramics in high-density } \\
\text { sintered state. }\end{array}$ & $\begin{array}{l}\text { Amann Girrbach AG, } \\
\text { Herrschaftswiesen, Koblach Austria. } \\
\text { Batch no. } 219542\end{array}$ \\
\hline $\begin{array}{l}\text { Dual cure, self-adhesive universal } \\
\text { resin cement capsule ( } \text { Rely } \mathbf{X}^{\mathrm{TM}} \\
\text { Unicem Aplicap }{ }^{\mathrm{TM}} \text { ). }\end{array}$ & $\begin{array}{l}\text { Powder: Glass powder, self-curing initiator, } \\
\text { silica, substituted pyrimidine calcium } \\
\text { hydroxide, peroxy compound, pigment, } \\
\text { light-curing initiators. } \\
\text { Liquid: Methacrylated phosphoric ester, } \\
\text { dimethacrylate (DMA), acetate, stabiliser, } \\
\text { self-curing \& light-curing Initiators. }\end{array}$ & $\begin{array}{l}\text { 3M ESPE, St.Paul, USA. } \\
\text { Batch no. } 310241\end{array}$ \\
\hline $\begin{array}{l}\text { Pure reagent of sulfuric acid (SA) } \\
\text { (Sulphouric acid } \mathbf{H}_{2} \mathrm{SO}_{4} \text { ). }\end{array}$ & $\begin{array}{l}\mathrm{H}_{2} \mathrm{SO}_{4} \text { having a minimum assay } 98 \%, \\
\text { molecular weight } 98.07 \text { and Sp.gr.1.84. }\end{array}$ & $\begin{array}{l}\text { ADWIC, El Nasr Pharmaceutical } \\
\text { Chemicals co. Egypt. } \\
\text { Batch no. S-0548111 }\end{array}$ \\
\hline $\begin{array}{l}\text { Pure reagent of acetone (Acetone } \\
\mathrm{CH}_{3} \mathrm{COCH}_{3} \text { ). }\end{array}$ & $\begin{array}{l}\mathrm{CH}_{3} \mathrm{COCH}_{3} \text { having a minimum assay } 99 \% \text {, } \\
\text { molecular weight } 58.08 \text {. }\end{array}$ & $\begin{array}{l}\text { ADWIC, El Nasr Pharmaceutical } \\
\text { Chemicals Co. Egypt. } \\
\text { Batch no. A-0038111 }\end{array}$ \\
\hline $\begin{array}{l}\text { Colorless-white-grey crystalline } \\
\text { powder (Aluminum Nitride }\{\text { AIN }\} \text { ). }\end{array}$ & $\begin{array}{l}\text { AlN } 99.8 \% \text { pure with } 1.8 \mu \mathrm{m} \text { average particle } \\
\text { size. Composing of: assay AlN } 99.9 \%, \mathrm{Fe} \\
0.033 \% \text {, and } \mathrm{Si} 0.0099 \% \text {. }\end{array}$ & $\begin{array}{l}\text { NOAH technologies corporation, San } \\
\text { Antonio, Texas, USA. Batch no. } \\
0242675 / 2.1\end{array}$ \\
\hline $\begin{array}{l}\text { White fine odorless solid powder } \\
\text { particles (Aluminum Sulfate } \\
\text { Hydrate } \\
\left.\left\{\mathrm{Al}_{2}\left(\mathrm{SO}_{4}\right)_{3} \cdot \mathbf{1 8} \mathbf{H}_{2} \mathrm{O}\right\}\right)\end{array}$ & $\begin{array}{l}\text { Analytical grade }\left\{\mathbf{A l}_{2}\left(\mathbf{S O}_{4}\right)_{3} . \mathbf{1 8} \mathbf{H}_{2} \mathbf{O}\right\} \text {, } \\
99.5 \% \text { purity, } 0-2 \mu \mathrm{m} \text { average particle size, a } \\
\text { molar mass of } 666,42 \mathrm{~g} / \mathrm{l} \& \text { a melting point } \\
\text { of } 90^{\circ} \mathrm{C} \text {. }\end{array}$ & $\begin{array}{l}\text { Chemia BRUGG AG, Switzerland. } \\
\text { Batch no. } 2331350\end{array}$ \\
\hline $\begin{array}{l}\text { Neutralizing agent } \mathrm{NH}_{4} \mathrm{OH} \\
\text { (Ammonia solution }\left(\mathrm{NH}_{4} \mathbf{O H}\right) \text {. }\end{array}$ & $\begin{array}{l}\text { Analytical grade }\left(\mathrm{NH}_{4} \mathrm{OH}\right) \text { having a } \\
\text { minimum assay of } 25 \% \text {, a molecular weight } \\
\text { of } 35.05 \mathrm{~g} / \mathrm{mol} \text {. }\end{array}$ & $\begin{array}{l}\text { Honeywell, Burdick \& Jackson, } \\
\text { Wunstorfer StraBe, Seeize. Germany. } \\
\text { Batch no.A1890 }\end{array}$ \\
\hline $\begin{array}{l}\text { Laboratory reagent, CTAB surfactant } \\
\text { (Cetyl-Trimethyl-Ammonium } \\
\text { Bromide }(\mathrm{CTAB}),\left\{\mathrm{CH}_{3} \cdot\left(\mathrm{CH}_{2}\right)_{15}\right\} \\
\left.\left(\mathrm{CH}_{3}\right)_{3} \mathbf{N B r}\right) \text {. }\end{array}$ & $\begin{array}{l}\text { Analytical grade }\left\{\mathrm{CH}_{3} .\left(\mathrm{CH}_{2}\right)_{15}\right\}\left(\mathrm{CH}_{3}\right)_{3} \mathrm{NBr} \\
\text { having a molecular weight of } 364.47 .\end{array}$ & $\begin{array}{l}\text { The British DrugHouse LTD) B.D.H } \\
\text { Lab. Chemicals Division, POOLE } \\
\text { England. } \\
\text { Batch no. } 2874630\end{array}$ \\
\hline $\begin{array}{l}\text { Organic water-soluble synthetic } \\
\text { polymer (Poly Vinyl Alcohol (PVA) } \\
\left.\left(\mathbf{C}_{2} \mathbf{H}_{4} \mathbf{O}\right) \mathbf{n}\right)\end{array}$ & $\begin{array}{l}\left(\mathrm{C}_{2} \mathrm{H}_{4} \mathrm{O}\right) \text { n having a molecular weight of } \\
75000 \text { and degree of hydrolysis } 99 \% \text {. }\end{array}$ & $\begin{array}{l}\text { LOBA Chemie Pvt. Ltd. Laboratory } \\
\text { reagents and fine chemicals, Mumbai, } \\
\text { India. } \\
\text { Batch no.05315 }\end{array}$ \\
\hline $\begin{array}{l}\text { Deionized water using the ultra pure } \\
\text { water system. }\end{array}$ & & $\begin{array}{l}\text { Barnstead International, easypure II. } \\
\text { Batch no. D7381 }\end{array}$ \\
\hline
\end{tabular}




\section{Specimens preparation:}

Thirty densely sintered zirconia ceramic discs (15 $\mathrm{mm}$ in diameter and $3 \mathrm{~mm}$ in thickness) were fabricated from pre-sintered zirconia ceramic blocks using a CAD/CAM system (Amman Girrbach Ceramill motion CAD/CAM system, Austria.) with 3D scan Software. Specially designed Teflon model having the zirconia disc dimensions, was constructed. To obtain a 3-Dimensional (3D) image of the Teflon model, it was sprayed with a special scanning spray-marker and placed in scanning system then; the virtual model (disc) was then seen on the computer screen. The pre-sintered zirconia block was placed in the metal holder of the milling machine and fastened with the setscrew. For each zirconia block, the shrinkage factor determined by Amann Girrbach is provided on the blocks with a batch specific coding, which has to be input into the CAD software of the CAD/CAM system. The disc was milled with an oversize of approximately $20-25 \%$ to accommodate for further shrinkage during the sintering process giving the exact final dimensions of the required disc. Same process was repeated to end up with 30 milled discs used in this study. Full sintering of Y-TZP discs was achieved by using an electrically heating furnace (Amman Girrbach Ceramill Therm, Austria). The sintering program ran as programmed according to the producing company, until reaching the maximum temperature of $1450^{\circ} \mathrm{C}$.

The specimens were randomly divided into 2 main groups (I and II) according to the type of surface pre-coating ( $\mathrm{n}=15 \mathrm{discs} /$ group). Group I: Polished zirconia with the Ceramill polishlab kit (Table 1). Group II: Zirconia treated with concentrated sulfuric acid (SA) solution, which was heated up to boiling temperature for 15 to $20 \mathrm{~min}$, then rinsed with deionized water. This was used after numerous experimental trials to optimize the required concentration and time needed for using sulfuric acid with zirconia. The most efficient results producing roughness, as evaluated by SEM occurred with $\approx 100 \%$ concentrated SA for $20 \mathrm{~min}$. Each group was further subdivided into 3 subgroups (A, B, C) according to the type of surface coating ( $n=5$ discs/subgroup), respectively as follow: control uncoated group, surface coating of the zirconia with nano-structured alumina using aluminum nitride powder (AlN), and surface coating of the zirconia with solution of aluminum sulfate $\left(\mathrm{Al}_{2}\left(\mathrm{SO}_{4}\right)_{3} .18 \mathrm{H}_{2} \mathrm{O}\right)$ respectively. All zirconia discs were ultrasonically cleaned (Ultrasonic cleaner GB-2500B, China) in acetone and deionized water (Table 1) for $5 \mathrm{~min}$ in each solvent preliminary to the experimental laboratory coating.

\section{Coatings preparation of the zirconia discs}

Nano-alumina deposition on Y-TZP, as a surface coating required 2 main laboratory steps:

\section{Precipitation of Boehmite (AlOOH)}

The 2 aluminum ion precursors used were for the surface coating namely: aluminum nitride (AIN) and aluminum sulfate $\mathrm{Al}_{2}\left(\mathrm{SO}_{4}\right)_{3}$ (Table 1$)$.

\section{Surface coating of the zirconia with nano-structured alumina using AlN powder}

A diluted aqueous suspension containing 3 $\mathrm{wt} \%$ of AlN powder was prepared by dispersing $6 \mathrm{~g}$ of AlN powder in $200 \mathrm{ml}$ (for each subgroup) of deionized water. In a glass beaker equipped with $\mathrm{pH}$ electrode (HANNA instruments $\mathrm{pH} 211$, Microprocessor $\mathrm{pH}$ Meter, Woonsocket, USA.) \& a thermometer, the water was first preheated to the desired temperature $\left(75^{\circ} \mathrm{C}\right)$ under constant stirring. Y-TZP substrates were then immersed, followed by dispersing the AIN powder into the water for 20 min. The $\mathrm{pH}$ was monitored during the vigorous stirring needed to homogenize the suspension. The coated substrates were removed, the hydrolyzed powders were separated by filtration and both were rinsed with deionized water and subsequently airdried in an oven for $2 \mathrm{~h}$ at $110^{\circ} \mathrm{C}$. Samples were then 
stored in plastic airtight containers for subsequent analysis ${ }^{(19,23)}$.

\section{Surface coating of the zirconia with nano-structured alumina using $\mathrm{Al}_{2}\left(\mathrm{SO}_{4}\right)_{3}$ powder:}

Prior to coating of the zirconia substrates with $\mathrm{Al}_{2}\left(\mathrm{SO}_{4}\right)_{3}$ powder, a turbidity test was performed. Turbidity is a parameter reflecting the degree of dispersion of a prepared solution, where a higher value represents higher dispersion efficiency of the solution. The solution turbidity was measured using Turbidity Meter (HANNA Instruments, HI 93703, Microprocessor, Woonsocket, USA), where a mixture of $1.5 \mathrm{M}$ of $\mathrm{NH}_{4} \mathrm{OH}$ and $0.25 \mathrm{M} \mathrm{Al}_{2}\left(\mathrm{SO}_{4}\right)_{3}$ solution was stirred in $50 \mathrm{ml}$ double distilled water. 5 $\mathrm{ml}$ of the mixture was added to the different laboratory prepared concentrations of CTAB (a dispersing agent, surfactant and a particle growth suppressing agent), $\left(10^{-4} \mathrm{M}, 5 \times 10^{-4} \mathrm{M}, 10^{-3} \mathrm{M}\right.$, and $5 \times 10^{-3} \mathrm{M}$, ) as presented in table 1 . The mixture was stirred for 20 min with magnetic stirrer. The suspension was then transferred to the measuring cell of the turbidity meter, and was left for settling. The readings of turbidity were recorded with time.

In a glass beaker Y-TZP substrates were inserted, with $\mathrm{pH}$ electrode (HANNA instruments $\mathrm{pH}$ 211, Microprocessor $\mathrm{pH}$ Meter, Woonsocket, USA) to monitor the change in $\mathrm{pH}$ by adding the base solution of $1.5 \mathrm{M}$ of $\mathrm{NH}_{4} \mathrm{OH}$ to the aluminum salt $0.25 \mathrm{M}$ $\mathrm{Al}_{2}\left(\mathrm{SO}_{4}\right)_{3}$ solution at room temperature ${ }^{[24]}$. CTAB was added followed by the addition of PVA (Poly Vinyl Alcohol, Organic water-soluble synthetic polymer) under constant stirring for $20 \mathrm{~min}$. The $\mathrm{pH}$ of the gels formed reached 8; the solution was subsequently centrifuged at $3000 \mathrm{rpm}$ for $10 \mathrm{~min}$ to separate the precipitates from the solution. Ageing of the gel was done for $180 \mathrm{~d}$ or for $20 \mathrm{~d}$ at $60^{\circ} \mathrm{C}$ resulted in crystalline boehmite. In this study the aging part was substituted by autoclaving (ALP Co., Ltd. Tokyo, Japan) the whole beaker for $30 \mathrm{~min}$ at $121^{\circ} \mathrm{C}$ with $0.1 \mathrm{MPa}$ pressure, in a trial to accelerate the transformation process from the amorphous gel into nano-boehmite ${ }^{[24]}$. Samples were subsequently air-dried in an oven for $2 \mathrm{~h}$ at $110^{\circ} \mathrm{C}$ and were stored in plastic airtight containers for subsequent analysis.

\section{Formation of nano-alumina:}

The dried samples were further thermally treated in an electric resistance oven (Thermolyne Benchtop Industrial Furnace, Thermo SCIENTIFIC, Massachusetts, USA) in platinum crucible in atmospheric air at $900^{\circ} \mathrm{C}$ for $1 \mathrm{~h}$, at a heating rate of $10^{\circ} \mathrm{C} / \mathrm{min}$, in order to transform the Nanoformed boehmite into the desired nano-alumina coatings ${ }^{[19,23]}$. Samples were then stored for subsequent analysis.

\section{Powder and coating characterization:}

\section{Crystalline phase identification}

X-ray diffractions (XRD) were performed to identify the crystalline phases after the hydrolysis and the heat treatment procedures made regarding both subgroups (B: AlN and $\mathbf{C}$ : $\left.\mathrm{Al}_{2}\left(\mathrm{SO}_{4}\right)_{3}\right)$. The coated zirconia substrates were identified using thin film X-ray Diffractometer (PANalytical X'Pert Pro, Netherlands). The surfaces of the samples were scanned with copper target $(\mathrm{Cu} \mathrm{K} \alpha) \mathrm{X}$-ray from 4 to $70^{\circ}, 2 \theta\left({ }^{\circ}\right)$ with a step size of 0.02 and $0.4 \mathrm{~s}$ step interval. While the remaining powders were identified using X-ray Diffractometer (D8 ADVANCE тм, BRUKER-AXS, Germany), the powders were scanned using copper target $(\mathrm{Cu} \mathrm{K \alpha})$ X-ray from 4 to $70^{\circ}, 2 \theta\left(^{\circ}\right)$ with a step size of 0.02 and $0.4 \mathrm{~s}$ step interval. The XRD analysis was done for the samples before and after heat treatment to $900^{\circ} \mathrm{C}$.

\section{Surface microstructure examination:}

Scanning electron microscope (SEM) (Quanta ${ }^{\mathrm{TM}}$ 250 FEG, FEI Company, Netherlands) was used to examine the specimens' surface microstructures. Sintered, polished and sulfuric acid treated zirconia 
discs were first examined followed by the zirconiacoated discs of subgroups $(\mathrm{B}, \mathrm{C})$ after thermal treatment at $900^{\circ} \mathrm{C}$. All samples were mounted on coded carbon stubs. The specimens were sputter coated with $10 \AA$ gold platinum and observed at the top view with various magnification powers. A voltage of $30 \mathrm{KV}$ was used.

\section{RESULTS}

\section{Surface coatings of the zirconia discs:}

\section{Precipitation of boehmite (AlOOH) from AlN:}

Once exposed to hot water, the dispersed AlN powder in the presence of the Y-TZP specimens vigorously reacts with water and started decomposing forming aluminum hydroxide and ammonia according to the following equation.

$$
\mathrm{AlN}+2 \mathrm{H}_{2} \mathrm{O} \longrightarrow \mathrm{AlOOH}+\mathrm{NH}_{3}
$$

The reaction of AlN powder with water is exothermic; there was a temperature rise from 75 to $80{ }^{\circ} \mathrm{C}$ within the $1^{\text {st }}$ few min of the reaction and eventually returned back to $75^{\circ} \mathrm{C}$ at the end. The released ammonia increased the $\mathrm{pH}$ value of the suspension reaching 9.3 to 9.6 after $20 \mathrm{~min}$.

\section{Precipitation of boehmite (AlOOH) from $\mathrm{Al}_{2}\left(\mathrm{SO}_{4}\right)_{3} .18 \mathrm{H}_{2} \mathrm{O}$ :}

The turbidity test results revealed that dispersion increases with $\mathrm{CTAB}$ concentration and reaches a maximum value at $5 \times 10^{-3} \mathrm{M}$ of $\mathrm{CTAB}$ with the solution mixture (Fig. 1). A sharp decrease in dispersion was observed at concentration less than $10^{-3} \mathrm{M}$ of CTAB. This could be explained as follow, at low $\mathrm{CTAB}$ concentrations, before the formation of surface aggregates of $\mathrm{CTAB}$ on the boehmite surface, adsorbed CTAB molecules distribute randomly on the surface (i.e. horizontally oriented). In this case, moderate dispersion values of the particles were obtained. As the surfactant concentration increases, more surfactant molecules are adsorbed at the water/ $\mathrm{Al}_{2}\left(\mathrm{SO}_{4}\right)_{3}$ interface (i.e. obliquely and vertically oriented). This resulted in further increase in dispersion forming a compact surfactant layer on the boehmite surface and reaching the highest dispersion behavior. An amorphous gel was first produced according to the following equation:

$$
\mathrm{Al}_{2}\left(\mathrm{SO}_{4}\right)_{3}+6 \mathrm{NH}_{4} \mathrm{OH} \longrightarrow 2 \mathrm{Al}(\mathrm{OH})_{3}+3\left(\mathrm{NH}_{4}\right)_{2} \mathrm{SO}_{4}
$$

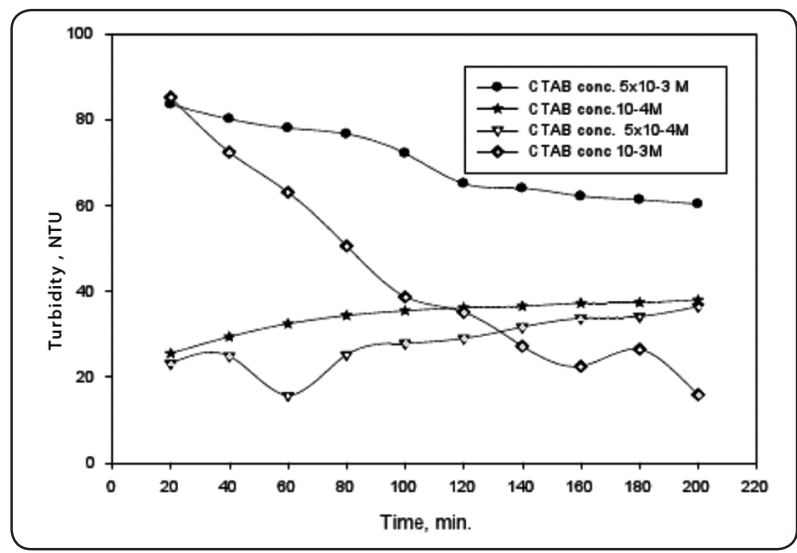

Fig. (1) Effect of different CTAB concentrations on boehmite dispersion.

The received amorphous gel was then transformed into boehmite, after autoclaving the whole beaker containing the solution gel with the substrates.

\section{Formation of nano-alumina:}

The morphology of the coating after heattreating the zirconia samples for both coating groups to $900^{\circ} \mathrm{C}$ remained basically unchanged till this temperature.

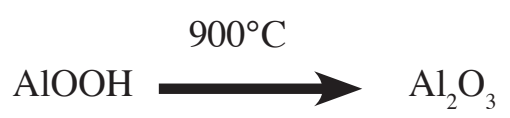

The phase changes from boehmite through $\mathrm{Al}_{2} \mathrm{O}_{3}$ are known to be topotactic (i.e. changes in crystal structure are accomplished without changes in crystalline morphology). The precipitated boehmite lamellae thermally decomposed forming a

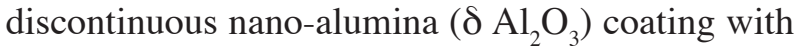
the original coating morphology preserved. 


\section{Surface characterization of the specimens:}

\section{Crystalline phase identification (XRD analysis):}

Mineralogical analysis of the sintered zirconia specimens' revealed only tetragonal phase (at $2 \boldsymbol{\theta}$ $\left.\left(^{\circ}\right): 30.2,34.6,35.2,50.2,61.1,74.4\right)$. The XRD pattern of the hydrolyzed AlN powder used for coating the zirconia groups (IB, IIB) showed wide peaks of nano-semi-crystalline (3 to $6 \mathrm{~nm}$ ) boehmite $(\mathrm{AlOOH})$ crystals (at $2 \boldsymbol{\theta}\left(^{\circ}\right)$ : 13.5, 14.2, 28.03, $48.5,64.8)$. Peaks of AlN were visible (at $2 \boldsymbol{\theta}\left({ }^{\circ}\right)$ : $33.1,36,37.8,49.7,59.3,65.9$ ) as seen in (Fig.2A). Upon thermal treatment of the boehmite at $900^{\circ} \mathrm{C}$ aluminum oxide, nano-alumina $\left(\delta \mathrm{Al}_{2} \mathrm{O}_{3}\right)$ peaks were identified (at $2 \boldsymbol{\theta}\left(^{\circ}\right.$ ): 19.1, 24.9, 32.5, 45.3, 67) having crystallite size ranging from 3 to $14 \mathrm{~nm}$, along with peaks of remaining Aluminum Nitride were visible (Fig.2A). On the other hand, The XRD analysis of the $\mathrm{Al}_{2}(\mathrm{SO} 4)_{3}$ solution used for coating the zirconia groups (IC, IIC) revealed at first amorphous aluminum gel before aging, (Fig.2B). While after centrifugation and autoclaving, wide peaks of nano-boehmite ( 3 to $4 \mathrm{~nm})(\mathrm{AlOOH})$ were identified (at $2 \boldsymbol{\theta}\left(^{\circ}\right)$ : 16, 28.2, 38.7, 49, 64.8) (Fig.2B). After thermal treatment of the boehmite at $900^{\circ} \mathrm{C}$, aluminum oxide, nano-alumina $\left(\delta \mathrm{Al}_{2} \mathrm{O}_{3}\right)$ peaks were identified (at $2 \boldsymbol{\theta}\left(^{\circ}\right)$ : $37.1,45.8,66.9$ ), having crystallite size ranging from 3 to $9 \mathrm{~nm}$, (Fig.2B).

The XRD analysis of zirconia coating using AlN (subgroup B), revealed peaks of semi-crystalline nano-boehmite $(\mathrm{AlOOH})$ at $2{ }^{\circ}$ Theta angles: 13.9, 28.1, 48.8, having crystallite size ranging from 3 to $6 \mathrm{~nm}$. Peaks of AlN were also visible (at $2 \boldsymbol{\theta}$ $\left(^{\circ}\right): 33.2,36,37.9,49.8,59.3,66$ ), (Fig.2C). After the heat treatment of boehmite coated zirconia at $900^{\circ} \mathrm{C}$, nano-alumina $\left(\mathrm{Al}_{2} \mathrm{O}_{3}\right)$ peaks were noticed (at $2 \boldsymbol{\theta}\left({ }^{\circ}\right)$ : 19.6, 39.4, 45.8, 67.3), having crystallite size ranging from 3 to $14.7 \mathrm{~nm}$ along with peaks of remaining AlN were visible, (Fig.2C).
Finally, the XRD analysis of the zirconia coating using $\mathrm{Al}_{2}(\mathrm{SO} 4)_{3}$ (subgroup $\mathrm{C}$ ) following the autoclaving step, revealed wide peaks of nanoboehmite (AlOOH) (at $\left.2 \boldsymbol{\theta}\left(^{\circ}\right): 28.2,38.07,64.01\right)$, with crystallite size ranging from 3 to $6 \mathrm{~nm}$ (Fig.2D). Nano-alumina peaks $\left(\mathrm{Al}_{2} \mathrm{O}_{3}\right)$, were identified, coating the zirconia after heat treatment at $900^{\circ} \mathrm{C}$ (at $2 \boldsymbol{\theta}\left(^{\circ}\right.$ ): $35.1,37.4,45.4,67.03$ ) having crystallite size ranging from 3 to $9 \mathrm{~nm}$, (Fig.2D).

\section{Surface Microstructure (SEM Examination):}

The SEM of sintered zirconia specimen (control group) revealed a densely rounded grained structure with minimum porosities (Fig.3). On the other hand, sulfuric treated zirconia revealed smaller particle size with more porosity; more contrast than the sintered specimen pinpointing the etching pattern of the sulfuric acid used (Fig.4). While, polished zirconia specimen showed only surface striations and shallow grooves, (Fig.5).

The SEM micrograph of the coated zirconia specimens, AlN subgroups (IB, IIB), revealed a good surface coverage of the alumina coating for polished and sulfuric acid treated zirconia (Figs.6, 7), appearing as bundles with nano-sized interconnected lamellas, interlocking at various directions. It can be seen that coating of alumina on the sulfuric treated zirconia specimen showed better and full coverage of lamellas than on polished one.

The SEM micrograph of the coated zirconia specimens with $\mathrm{Al}_{2}\left(\mathrm{SO}_{4}\right)_{3}$ subgroups, had a starshaped, flattened leaf-like structure of alumina coating for polished zirconia (IC), randomly positioned, most of which in a perpendicular position to the flat zirconia substrate (Fig.8). On the other hand, the coating for sulfuric acid treated zirconia (IIC) had more deposition of alumina, better surface coverage with more and even randomization of the position of the deposited crystals of alumina, (Fig.14). 


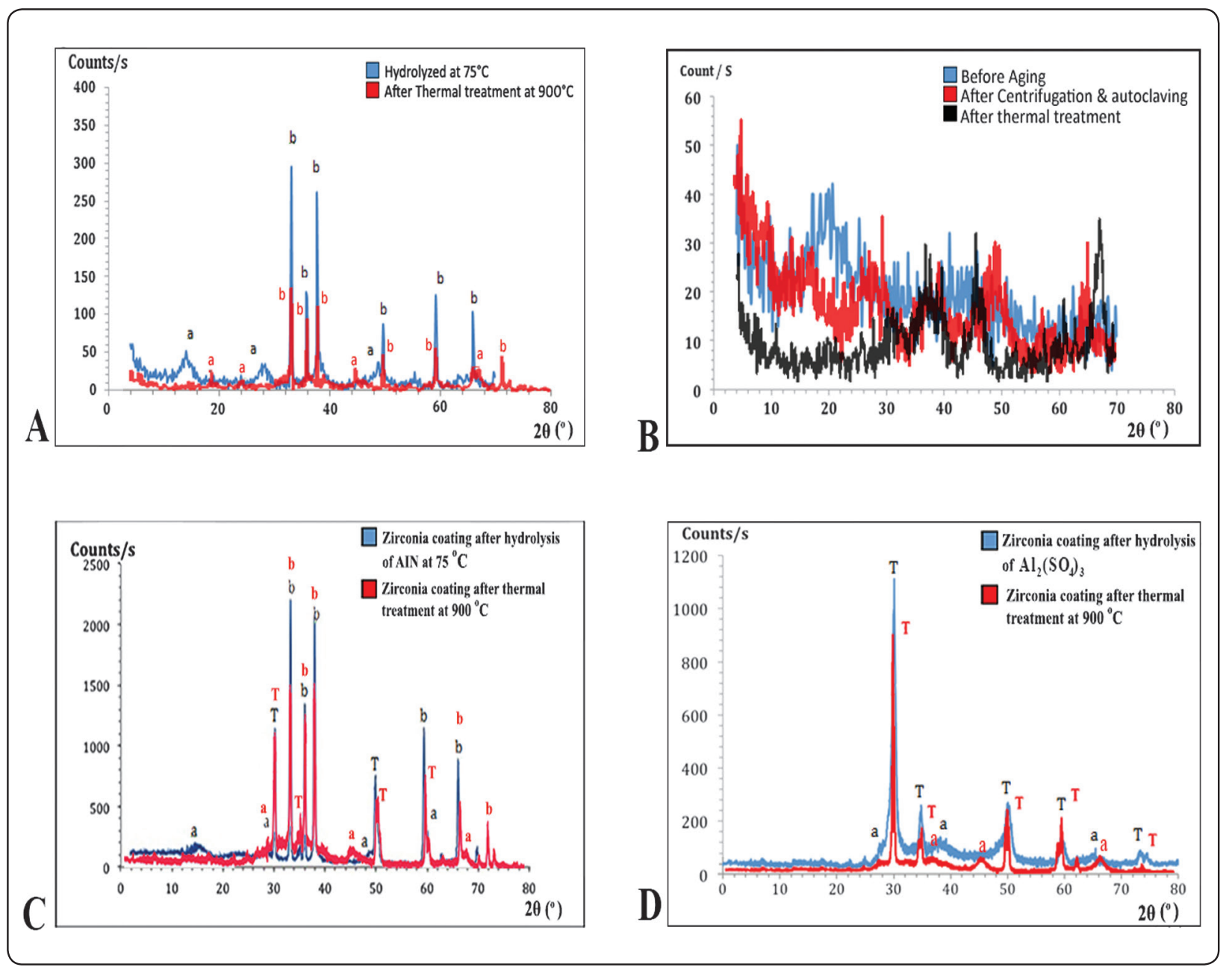

Fig. (2) XRD patterns of: (A): AlN powder: (In blue) Hydrolyzed at $75^{\circ} \mathrm{C}$ showing the formation of: (a) Nano-boehmite (AlOOH), (b) Remnants of AlN. (In red) After thermal treatment to $900{ }^{\circ} \mathrm{C}$ showing the formation of: (a) Nano- $\mathrm{Alumina} \mathrm{Al}_{2} \mathrm{O}_{3}$ (b) AlN. (B): Hydrolyzed $\mathrm{Al}_{2}\left(\mathrm{SO}_{4}\right)_{3}$ powder: (In blue) Before aging, showing the formation of an amorphous structure; (In red) After centrifugation and autoclaving, showing nano-boehmite ( $\mathrm{AlOOH}) ;\left(\right.$ In black) After thermal treatment to $900{ }^{\circ} \mathrm{C}$, showing the formation of nano-alumina $\mathrm{Al}_{2} \mathrm{O}_{3} .(\mathbf{C})$ : XRD pattern of zirconia coated (In blue $)$ with nano-boehmite $(\mathrm{AlOOH})$ (after hydrolysis of AlN powder, showing the formation of: (a) Nano-boehmite (AlOOH), (b) AlN, (T) Tetragonal zirconia. (In red) Zirconia coated with nano-alumina $\left(\mathrm{Al}_{2} \mathrm{O}_{3}\right)$ after thermal treatment of boehmite to $900{ }^{\circ} \mathrm{C}$, showing the formation of: (a) Nano-Alumina, (b) AlN, $\left(\mathrm{Al}_{2} \mathrm{O}_{3}\right)$, (T) tetragonal zirconia. (D): XRD pattern of zirconia coated (In blue ) with Nanoboehmite $(\mathrm{AlOOH})$ after autoclaving (resulting from the hydrolysis of $\mathrm{Al}_{2}\left(\mathrm{SO}_{4}\right)_{3}$ powder, showing the formation of: (a) boehmite $(\mathrm{AlOOH})(\mathrm{T})$ tetragonal zirconia. (In red) zirconia coated with nano-alumina $\left(\mathrm{Al}_{2} \mathrm{O}_{3}\right)$ after thermal treatment of boehmite to $900{ }^{\circ} \mathrm{C}$, showing the formation of: (a) nano-Alumina $\left(\mathrm{Al}_{2} \mathrm{O}_{3}\right)$, (T) tetragonal zirconia. 


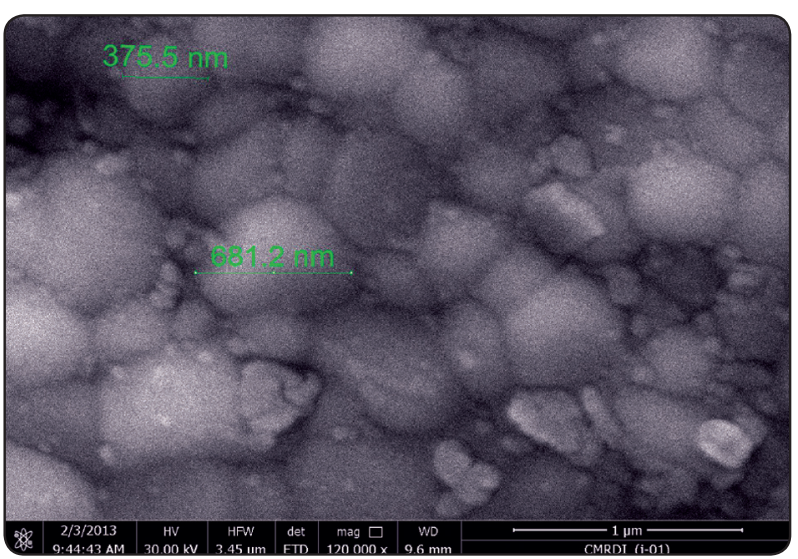

Fig.(3) SEM micrograph of sintered zirconia specimen revealing a densely rounded grained structure with minimum porosities. Top view, Magnification 120000X.

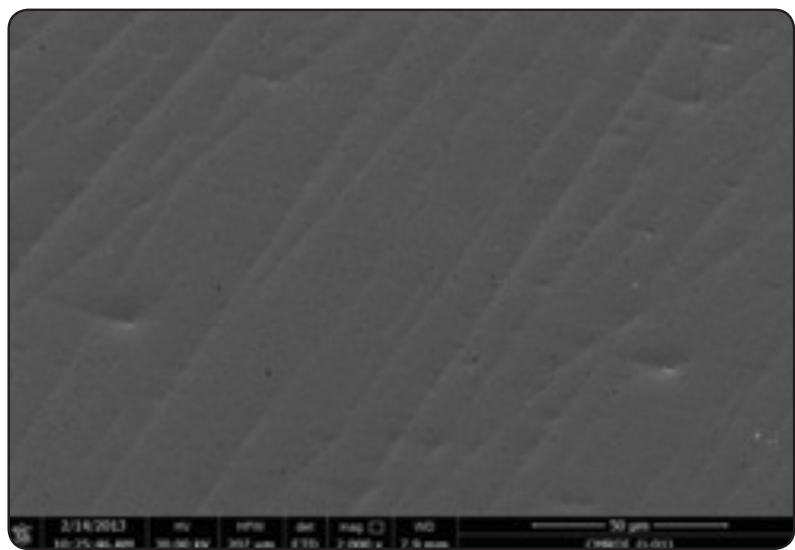

Fig. (5) SEM micrograph of polished zirconia specimen showing only some surface striations and shallow grooves on the smooth surface. Top view, Magnification 2000X.

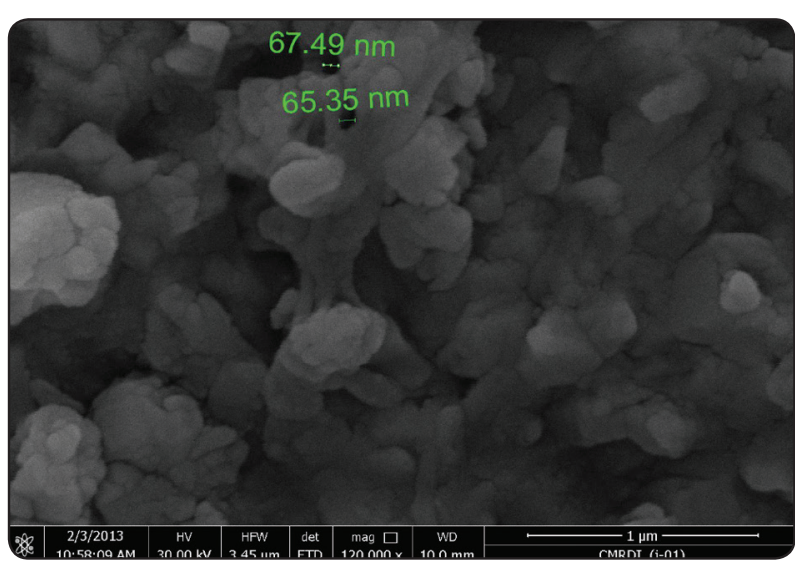

Fig. (4) SEM micrograph of sulfuric acid treated zirconia specimen showing smaller particle size with created porosities pinpointing the etching pattern of the sulfuric acid used. Top view, Magnification 120000X.

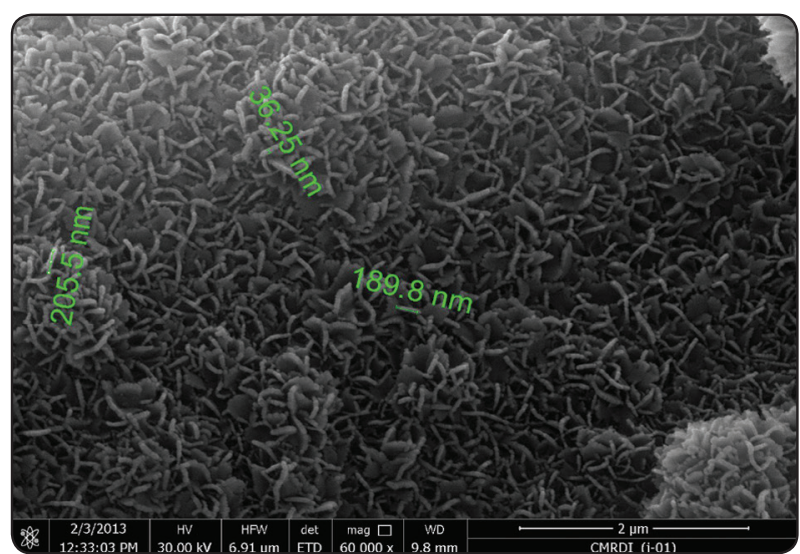

Fig. (6) SEM micrograph of nano-alumina coating on polished specimen (using AlN precursor) revealed a good surface coverage of the alumina coating, with bundles showing the average lamellae size. Top view, Magnification $60000 X$.

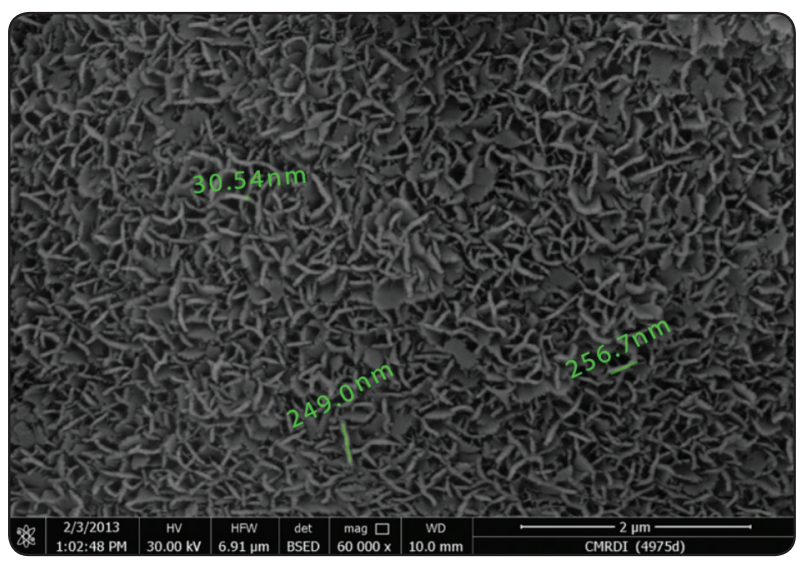

Fig. (7) SEM micrograph of nano-alumina coating on sulfuric acid treated specimen (using AlN precursor) showing condensation of more nano-sized interconnected lamellae, interlocking at various directions. Better and full coverage of alumina lamellas zirconia surface coating can be seen. Top view, Magnification 60000X. 


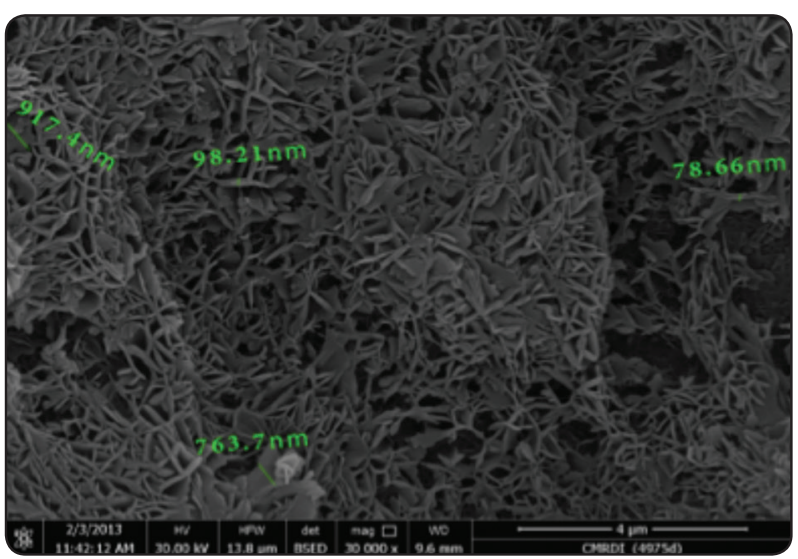

Fig.(8) SEM micrograph of nano-alumina coating on polished specimen using $\mathrm{Al}_{2}\left(\mathrm{SO}_{4}\right)_{3}$. Star-shaped, flattened structure of alumina coating, were randomly positioned. Top view, Magnification $60000 \mathrm{X}$.

\section{DISCUSSION}

Nanotechnology is the study of manipulating matter on an atomic and molecular scale. It is the production of functional materials and structures sized between 0.1-100 nm by various chemical or physical methods ${ }^{(25)}$. Nanostructured materials offer better performance than their larger particle sized counterparts. This is due to their extremely high surface to volume ratio and unusual chemical and electronic synergistic effects. Nano-sized-alumina coating using AlN as aluminum ion precursor has been one of the most recently introduced zirconia pretreatment method used for improving the adhesive potential of zirconia to resin cements ${ }^{(19-24)}$. However, the use of AlN possessed some obstacles regarding its high expenses and unavailability due to health hazards and national security restrictions. Therefore, $\mathrm{Al}_{2}\left(\mathrm{SO}_{4}\right)_{3}$ has been used in the current study as a cheaper and easily available aluminum precursor.

Generally, the reactivity of aluminum ion powder precursors in diluted aqueous suspensions has been known to provide challenge to chemists, since dispersion in water results in the formation of various aluminum hydroxides. The hydrolysis

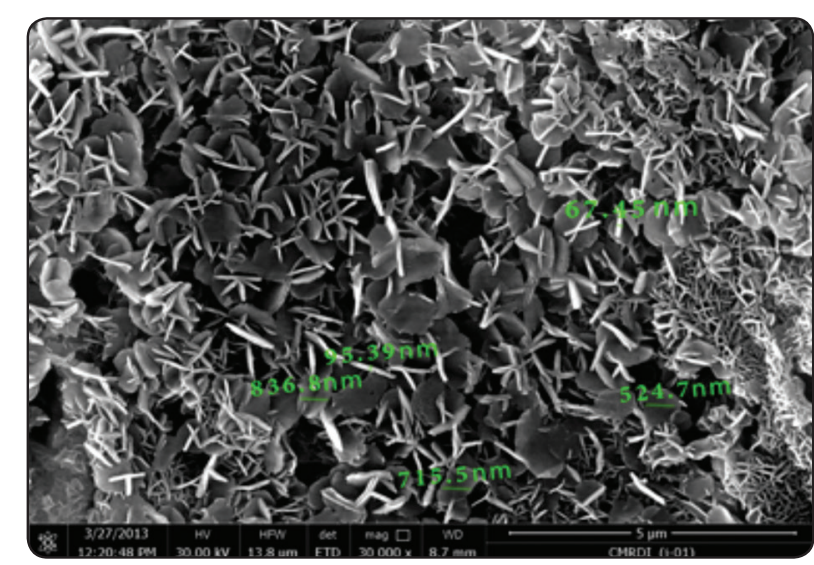

Fig. (9) SEM micrograph of nano-alumina coating on sulfuric acid treated specimen using $\mathrm{Al}_{2}\left(\mathrm{SO}_{4}\right)_{3}$. More deposition of the flattened leaf-like structure of alumina can be seen with even randomization. Top view, Magnification $30000 \mathrm{X}$.

process is made of 3 interdependent stages. The first stage (induction period), is the initial slow rate of hydrolysis in which a thin layer of amorphous aluminum hydroxide forms on the surface of the powder particles. The second stage is the nucleation, crystallization and growth of aluminum monohydroxide, namely boehmite (AlOOH). This stage is accompanied by rapid increase in the concentration of the dissolved aluminum ions in the suspension. When a saturation condition is reached, the heterogeneous nucleation and growth of lamellar nano-crystals of aluminum oxyhydroxide $(\mathrm{AlOOH})$ occurred, on the immersed substrate surfaces ${ }^{(26)}$. Several factors affect the formation of crystalline aluminum hydroxide, such as the $\mathrm{pH}$ of the solution in contact with a formed amorphous phase. The $\mathrm{pH}$ value provides the driving force for the nucleation phenomenon, the $\mathrm{OH} / \mathrm{Al}$ ratio of the solution, the aluminum and base concentration in the solution, the rate of base addition and the temperature ${ }^{(26)}$. The third stage, growth of bayerite $\left(\mathrm{Al}(\mathrm{OH})_{3}\right)$ occurs. During suspension aging, part of the formed crystalline boehmite dissolve, recrystallize and grow to larger elongated, rod-like crystalline polymorph aluminum trihydroxide, namely bayerite 
$\left(\mathrm{Al}(\mathrm{OH})_{3}\right)^{(27)}$. The starting temperature and the aging time, strongly influence the reaction products and their morphologies. At room temperature, the only crystalline reaction product is the large submicron elongated rod-like bayerite crystals ( $\mathrm{Al}$ $(\mathrm{OH})_{3}$ ) regardless of the ageing time ${ }^{(26)}$. However, at elevated temperatures, the first crystalline product is boehmite $(\mathrm{AlOOH})$ and no bayerite peaks were found in XRD (Figs. 2A, 2B). The hydrolysis time was up to $20 \mathrm{~min}$. since with prolonged ageing time the bayerite conversion takes place with the dissolution of part of the poorly crystalline nanoboehmite with recrystallization of large particles bayerite ${ }^{(27)}$.

According to the XRD analysis, the tetragonal phase was only identified in the sintered zirconia. This was due to the monoclinic to tetragonal transformation, which occurred during the sintering process and the stability effect of $\mathrm{Y}_{2} \mathrm{O}_{3}{ }^{(10)}$. The results of the XRD analysis of the coated zirconia after hydrolysis of AlN powder (Figs.2A, 2C) were in agreement with several studies ${ }^{(26-30)}$. It has been reported that hydrolysis of $\mathrm{AlN}$ powder for $20 \mathrm{~min}$ at high temperatures $\left(75-80{ }^{\circ} \mathrm{C}\right)$, resulted in peaks of nano-boehmite only without any bayerite peaks and even after prolonged ageing time, peaks of unreacted AlN in the XRD pattern were found. Additionally, at high temperatures, the greater solubility of the amorphous hydroxide maintains the supersaturation at a higher level and the crystallization had to proceed more quickly, where there is no time for the slow recrystallization of bayerite to occur. Therefore, crystallization of boehmite occurred ${ }^{(31)}$. After heat treatment of nano-boehmite to $900^{\circ} \mathrm{C}$ (for $1 \mathrm{~h}$ at a heating rate of $10{ }^{\circ} \mathrm{C} / \mathrm{min}$ ), the aluminum oxyhydroxide lamellas were transformed to a $\delta$ nano-alumina coating with the original coating morphology preserved (Fig.2C).

The XRD analysis results with the SEM micrographs examination suggested good chances for increasing and improving the available surface area of zirconia and provide more space for the resin cement latter on. As the SEM micrographs of nanoalumina coating on polished and sulfuric acid pretreated specimens (using AlN precursor) revealed a good surface coverage of the nano-alumina coating. The coating appeared as bundles of nano-sized interconnected lamellae, interlocking at various directions. Furthermore, coating of alumina on the sulfuric acid treated zirconia specimen showed better and full coverage of lamellae than on polished one (Figs. 6,7). In order to explain these findings, the SEM micrographs of sintered zirconia (control), sulfuric acid etched and/or polished zirconia surfaces were examined (Figs. 3-5). The SEM micrographs of sintered zirconia (control) specimen revealed a densely rounded grained structure with minimum porosities, indicating proper degree of sintering yet each grain has its intact boundary margin (Fig.3). On the other hand, sulfuric treated zirconia revealed smaller particle size with more porosity; more contrast than the sintered specimen pinpointing the etching pattern of the sulfuric acid used (Fig.4). While, polished zirconia specimen showed only surface striations and shallow grooves, (Fig.5). Etching involves removal of material from the sample surface by the acid. The bonding of atoms, ions and molecules is weaker at exposed positions such as at grain boundaries and imperfections, therefore etching first initiated at those locations, yielding additional nucleation sites for extra boehmite deposition. This might provide latter on larger retentive surface area for micro-mechanical interlocking for zirconia/ resin cement bonding.

It worth to emphasize that upon increasing the thermal treatment temperature of the coating up to $1200^{\circ} \mathrm{C}$, the $\delta$ to $\alpha$ phase transition of the nano-sized alumina lamellas $\left(\alpha \mathrm{Al}_{2} \mathrm{O}_{3}\right)$ occurred through growth of alumina crystals. They started to coarse then sintered (phase change is accompanied by change in porosity), forming a continuous nano-alumina coating, and shrunk in size. Therefore, less surface area available for bonding would result giving lower 
chances for good resin/zirconia adhesion. This result was in agreement with several studies ${ }^{(19,23,32)}$. Furthermore, Jevinkar et al. ${ }^{(19)}$ suggested that the coating morphology was preserved with thermal treatment to $900^{\circ} \mathrm{C}$ after the phase transformation process, which, intern maintained the large submicron-retentive areas on Y-TZP substrate with the potential for promoting resin bonding.

Concerning the XRD analysis of the zirconia coated with $\mathrm{Al}_{2}\left(\mathrm{SO}_{4}\right)_{3}$, the hydrolyzed powder revealed at first amorphous aluminum gel before aging, (Fig.2B). On the other hand, after solution centrifugation and autoclaving, wide peaks of nanoboehmite $(\mathrm{AlOOH})$ only were identified, which transformed to $\delta$ nano-alumina by heat treatment (Fig. 2B). This could be related to the strong affinity of $\mathrm{SO}_{4}^{-}$for aluminum, forming the first reaction product as amorphous aluminum hydroxide. Then aging would accelerate the transformation process and crystallization of the amorphous gel into crystalline boehmite ${ }^{(24,33)}$.

Although the use of $\mathrm{Al}_{2}\left(\mathrm{SO}_{4}\right)_{3}$ as aluminum ion precursor for nano-alumina coating of zirconia could promote the adhesion of resin to zirconia, it seems to be less effective than AlN. This could be related to the differences in coating features (Figs. 6-9). The SEM micrographs of the coated zirconia specimens with $\mathrm{Al}_{2}\left(\mathrm{SO}_{4}\right)_{3}$ subgroups(IC, IIC) possessed larger crystal size, star-shaped and flattened leaf-like structure of alumina coating with randomly positioned, most of which in a perpendicular position to the flat zirconia substrate were detected (Figs. 8, 9). Again the coating for sulfuric acid treated zirconia (IIC) had more deposition of alumina, better surface coverage with more and even randomization of the position of the deposited alumina crystals (Fig. 9) as compared with deposition of nano-alumina on polished zirconia surface (IC) as seen in (Fig.8).

After the establishing of a predictable controlled method for the precipitation of nano-alumina coating on Y-TZP zirconia with the suggested sulfuric acid surface pre-treatment, further research work is recommended to test the bonding abilities of nano-alumina coated zirconia to dental resin cements. Therefore, testing of nano-alumina coated zirconia/resin cement shear bond strength is under investigation.

\section{CONCLUSIONS}

Within the limits of this study, the following conclusions can be drawn:

1. Precipitation method of nano-alumina is a promising, yet complex method to be used for zirconia substrate according to both aluminum ions precursors.

2. Meticulous selection of alumina precursors, $\mathrm{pH}$, temperature and stirring time are crucial and sensitive parameters in the co-precipitation of alumina on zirconia substrates.

3. Aluminum nitride precursor provides superior zirconia nano-alumina coating quality than aluminum sulfate.

4. Sulfuric acid surface pre-treatment of zirconia improved the retentive quality of the nano-alumina coating.

\section{ACKNOWLEDGEMENTS}

The authors are grateful to The Faculty of Oral and Dental Medicine, Cairo University, Egypt, for financially supporting the purchasing of zirconia used in this study. Special thanks are owed to Dr. Hossam Moawad's Laboratory Cairo Dental Designs, for milling the zirconia blocks. Deepest thanks to the members of the chemical laboratory of the Central Metallurgical Research and Development Institute (CMRDI), for their guidance during the precipitation of nano-alumina \& surface characterization of the specimens. 


\section{REFERENCES}

1. Kitayama S, Nikaido T, Takahashi R, Zhu L, Ikeda M, Foxton RM, Sadr A, Tagami J. Effect of primer treatment on bonding of resin cements to zirconia ceramic. Dent Mater 2010, 26: 426-432.

2. Denry I, Kelly JR. State of the art of zirconia for dental applications. Dent Mater 2008, 24: 299-307.

3. Piascik JR, Swift EJ, Thompson JY, Grego S, Stoner BR. Surface modifications for enhanced silanation of zirconia ceramics. Dent Mater 2009, 25: 1116-1121.

4. Lohbauer U, Zipperle M, Rischka K, Petschelt A, Muller FA. Hydroxylation of dental zirconia surfaces: characterization and bonding potential. J Biomed Mater. Res B Appl Biomater 2008, 87: 461-467.

5. Thompson JY, Stoner BR, Pisscik JR, Smith R. Adhesion/ cementation to zirconia and other non-silicate ceramics: where are we now?. Dent Mater 2011, 27: 71-82.

6. Blatz MB, Sadan A, Kern M. Resin ceramic bonding: a review of literature. J Prosthet Dent 2003: 89 268-274.

7. Shen J, Kosmač T. Advanced Ceramics for Dentistry, first ed., Butterworth-Heinemann, Waltham, MA, 2014.

8. Yang B, Barloi A, Kern M. Influence of air abrasion on zirconia ceramic bonding using an adhesive composite resin. Dent Mater 2009, 26: 44-50.

9. Magne P, Paranhos MP, Burntt LM. New zirconia primer improves bond strength of resin-based cements. Dent Mater 2010, 26: 345-352.

10. Moon JE, Kim SH, Lee SR, Choi YS. The effect of preparation order on the crystal structure of yttria-stabilized tetragonal zirconia polycrystal and the shear bond strength of dental resin cements. Dent Mater 2011, 27: 651-663.

11. Matinlinna JP, Heikkinen T, Özcan M, Lassila LV, Vallitlu P. Evaluation of resin adhesion to zirconia ceramic using some organosilanes. Dent Mater 2006, 22: 824-831.

12. Lin J, Shinya A, Gomi H, Shinya A. Effect of self-adhesive resin cement and tribochemical treatment on bond strength to zirconia. Int J Oral Sci 2010, 2: 28-34.

13. Kawai N, Lin J, Youmaru H, Shinya A, Shinya A. Effects of three luting agents and cyclic impact loading on shear bond strengths to zirconia with tribochemical treatment. J Dent Sci 2012, 7: 118-124.

14. Derand T, Molin M, Kvam K. Bond strength of compos- ite luting cement to zirconia ceramic surfaces. Dent Mater 2005, 21: 1158-1162.

15. Kitayama S, Nikaido T, Maruoka R, Zhu L, Ikeda M, Watanabe A, Foxton RM, Miura H, Tagami J. Effect of an internal coating technique on tensile bond strengths of resin cements to zirconia ceramics. Dent Mater J 2009, 4: 446-453.

16. Aboushelib MN, Matinlinna JP, Salameh Z, Ounsi H. Innovations in bonding to zirconia-based materials. Part I Dent Mater 2008, 24: 1268-1272.

17. Casucci A, Osorio E, Osorio R, monticelli F, Toledano M, Mazzielli C Ferrari M. Influence of different surface treatments on surface zirconia frameworks. J Dent 2009, 37: 891-897.

18. Casucci A, Mazzitelli C, Monticelli F, ToledanoM, Osario R, Osario E, Papacchini F, Ferrari M. Morphological analysis of three zirconium oxide ceramics: Effect of surface treatments. J Dent 2010, 26: 751-760.

19. Jevnikar P, Krnel K, Kocjan A, Funduk N, Kosmač T, The effect of nano-structured alumina coating on resin-bond strength to zirconia ceramics. Dent. Mater 2010, 26: 688696.

20. Zhang S, Kocjan A, Lehmann F, Kosmač T, Kern M. Influence of contamination on resin bond strength to nanostructured alumina-coated zirconia ceramic. Eur J Oral Sci 2010, 118: 396-403.

21. Jevinkar P, Golobič M, Kocjan A, Kosmač T. The effect of nano-structured alumina coating on the bond strength of resin-modified glass ionomer cements to zirconia ceramics. J Eur Ceram Soc 2012, 32: 2641-2645.

22. Krnel K, Kocjan A, Kosmoc T. A simple method for the preparation of nanostructured aluminate coating. J Am Ceram Soc 2009, 92: 2451-2454

23. Kocjan A, Krnel K, Jevnikar P, Kosmac T. Nanostructured alumina coatings formed by a dissolution/precipitation process using AlN Powder Hydrolysis, in: R. Narayan, P. Colombo, D. Singh and J. Salem (Eds.), Advances in Bioceramics and Porous Ceramics II, John Wiley \& Sons, Inc., Hoboken, NJ, USA. 2010, pp. 251-260.

24. Prodromou K, Pavlatou A. Formation of aluminum hydroxide as influenced by aluminum salts and bases. Clays and Clay Miner 1995, 43:111-115.

25. http://en.wikipedia.org/wiki/Nanotechnology. 
26. Kocjan A, Krnel K, Kosmač T. The influence of temperature and time on the AlN powder hydrolysis reaction products. J Eur Ceram Soc 2008, 28: 1003-1008.

27. Yoldas BE. Hydrolysis of aluminum alkoxides and bayerite conversion. J Appl Chem Biotechnol 1973, 23: 803-809.

28. Kocjan A, Dakskobler A, Kosmač T. Evolution of aluminum hydroxides in diluted aqueous aluminum nitride powder suspensions. Cryst Growth Des 2012, 12: 1299-1307.

29. Kojcan A, Dakskobler A, Krnel K, Kosmač T. The course of hydrolysis and the reaction kinetics of AlN powder in diluted aqueous suspensions. J Eur Ceram Soc 2011, 31: 815-823.
30. Fukumoto S, Hookabe T, Tsubakino H. Hydrolysis behavior of aluminum nitride in various solutions. J Mater Sci 2000, 35: 2743-2748.

31. Krnel K, Dražič G, Kosmač T. Degradation of AlN powder in aqueous environments. J Mater Res 2004, 19: 1157 1163.

32. Barron A. Aluminum oxides, hydroxides, and hydrated oxides. Version1.2: Jan 25, 2010. http://creativecommomns/licenses/by/3.0/

33. Hsu PH, Bates TF. Formation of X-ray amorphous and crystalline aluminum hydroxides. Mineral Mag 1964, 33: 749-768. 